\title{
natureouTLOOK RICE
}

30 October 2014 / Vol 514 / Issue No 7524

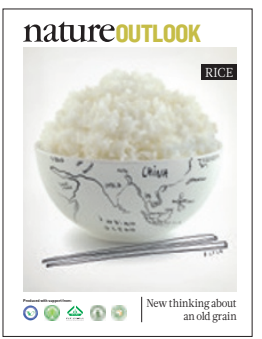

Cover art: Serge Bloch

\section{Editorial}

Herb Brody,

Michelle Grayson,

Chris Woolston,

Kathryn Miller

Art \& Design

Wesley Fernandes,

Mohamed Ashour

Christian Tate,

Andrea Duffy

Production

Karl Smart,

Ian Pope,

Robert Sullivan

Sponsorship

Stella Yan,

Yvette Smith

Marketing

Hannah Phipps

Project Manager

Anastasia Panoutsou

Art Director

Kelly Buckheit Krause

Publisher

Richard Hughes

Chief Magazine Editor

Rosie Mestel

Editor-in-Chief

Philip Campbell
$\mathrm{R}$ ice is not just another grain. For three billion people, it is a daily necessity (page S50). Since its domestication some 8,000 years ago (S58), rice has played a part in building civilizations, shaping societies and, most of all, feeding a growing world.

But the climate is changing, and much of the land that once went to paddies is being consumed by expanding cities. There is a realization that farmers cannot keep applying fertilizers and pesticides to their crops without environmental consequences. If rice is going to feed future populations - in Asia, Africa (S64) and beyond - scientists will have to help to improve yields.

Rice research involves scientists around the world. This year marked a milestone achievement: the publication of the genomes of 3,000 strains of rice will help to guide the creation of hardier, more productive crops (S60). Researchers are addressing a massive nutritional crisis by converting rice into a vehicle for vitamin A, but a combination of technical challenges and public opposition threatens the development of this 'golden' rice (S55). Scientists plan to retool the way in which rice harvests energy from the Sun (S52) and are tackling problems such as arsenic contamination (S62).

Many questions remain, but the biggest - will there be enough rice? - will take decades to decide. Governments and scientists can use that time to work together on the answer (S66).

We are pleased to acknowledge the financial support of the Institute of Genetics and Developmental Biology, Chinese Academy of Sciences (CAS); the Institute of Plant Physiology \& Ecology, Shanghai Institutes for Biological Sciences, CAS; the Institute of Botany, CAS; the Institute of Crop Science, Chinese Academy of Agricultural Sciences (CAAS); and the China National Rice Research Institute, CAAS, in producing this Outlook. As always, Nature has sole responsibility for all editorial content.

\section{Chris Woolston}

Contributing Editor

Nature Outlooks are sponsored supplements that aim to stimulate interest and debate around a subject of interest to the sponsor, while satisfying the editorial values of Nature and our readers expectations. The boundaries of sponsor involvement are clearly delineated in the Nature Outlook Editorial guidelines available at go.nature.com/e4dwzw

CITING THE OUTLOOK

Cite as a supplement to Nature, for example, Nature Vol. XXX, No. XXXX Suppl., Sxx-Sxx (2014).

VISIT THE OUTLOOK ONLINE

The Nature Outlook Rice supplement can be found at

http://www.nature.com/nature/outlook/rice

It features all newly commissioned content as well as a selection of

relevant previously published material.
All featured articles will be freely available for 6 months. SUBSCRIPTIONS AND CUSTOMER SERVICES For UK/Europe (excluding Japan): Nature Publishing Group, Subscriptions, Brunel Road, Basingstoke, Hants, RG21 6XS, UK Tel: +44 (0) 1256329242 . Subscriptions and customer services for Americas - including Canada, Latin America and the Caribbean: Nature Publishing Group, 75 Varick St, 9th floor, New York, NY 10013-1917, USA. Tel: +18663637860 (US/Canada) or +1 212726 9223 (outside US/Canada). Japan/China/Korea: Nature Publishing Group - Asia-Pacific, Chiyoda Building 5-6th Floor, 2-37 Ichigaya Tamachi, Shinjuku-ku, Tokyo, 162-0843, Japan. Tel: +81 33267875 CUSTOMER SERVICES

Feedback@nature.com

Copyright @ 2014 Nature Publishing Group

\section{CONTENTS}

\section{S50 RICE BY THE NUMBERS}

A good grain

A snapshot of global production, consumption and trade

S52 AGRIBIOTECHNOLOGY

\section{Blue-sky rice}

Researchers are working to increase rice yields to feed a growing population

S55 BIOTECHNOLOGY

Against the grain

Golden rice, which is being developed to help prevent vitamin A deficiency, has political and technical problems

S58 DOMESTICATION

The birth of rice

The competing claims of countries claiming to be the crop's origin

S60 YIELD

The search for the rice of the future

Researchers are working on small changes to make big improvements

S62 CONTAMINATION

The toxic side of rice

Investigations to prevent arsenic from contaminating this vital crop

S64 AGRICULTURE

The next frontier

Africa relies on rice imports but there is a move to self-sufficiency

S66 PERSPECTIVE

Time to unleash rice

Governments' interventions are not helping farmers, says Robert Zeigler

\section{COLLECTION}

S67 Genetic diversity and classification of Oryza sativa with emphasis on Chinese rice germplasm Wang, C. H. et al.

S75 Africa and Asia need a rational debate on GM crops Whitty, C.J.M.

S78 Genome-wide association analyses provide genetic and biochemical insights into natural variation in rice metabolism Chen, W. et al.

S86 The genome sequence of African rice (Oryza glaberrima) and evidence for independent domestication Wang, $M$. et al. 